\title{
Denying the Antecedent: \\ Its Effective Use in Argumentation
}

\author{
MARK STONE
}

Department of Philosophy

Furman University

Greenville, SC 29613

mark.stone@furman.edu

\begin{abstract}
Denying the antecedent is an invalid form of reasoning that is typically identified and frowned upon as a formal fallacy. Contrary to arguments that it does not or at least should not occur, denying the antecedent is a legitimate and effective strategy for undermining a position. Since it is not a valid form of argument, it cannot prove that the position is false. But it can provide inductive evidence that this position is probably false. In this role, it is neither defective nor deceptive. Denying the antecedent provides inductive support for rejecting a claim as improbable.
\end{abstract}

Résumé: Nier l'antécédent est une forme non valide d'un raisonnement qu'on désapprouve généralement comme une erreur formelle. Contrairement aux arguments fallacieux où elle se produit, nier l'antécédent est une stratégie légitime et efficace pour miner une position. Comme elle n'est pas une forme valide de l'argument, elle ne peut pas prouver que la position est fausse. Mais elle peut fournir une preuve inductive que cette position est probablement fausse. Dans ce rôle, elle est ni défectueuse, ni trompeuse. Nier l'antécédent peut fournir un soutien inductif pour rejeter une proposition comme improbable.

Keywords: Argument, argumentation, conditional, denying the antecedent, fallacy, undermine

\section{Introduction}

Denying the antecedent is universally recognized as a formal fallacy in reasoning because arguments using this form of reasoning are invalid. It is possible for them to have true premises but a false conclusion. As one moves outside the sphere of formal logic and begins to evaluate arguments, significant disagreement exists regarding how we should treat denying the antecedent. One source of disagreement questions whether denying the antecedent occurs anyplace besides logic books where examples are contrived to illustrate that it is an invalid argument form (Finocchiaro 2005: 113-20). The main argument here is that what may look like a fallacy in reasoning can usually be interpreted charitably as an argument of a

(C) Mark Stone. Informal Logic, Vol. 32, No. 3 (2012), pp. 327- 


\section{Mark Stone}

different form that commits no fallacy. Although this general point is more difficult defend simply because of its scope, this strategy of charitable interpretation has been applied persuasively to argue that the fallacy of denying the antecedent virtually never occurs (Burke 1994: 23-30). The approach that Burke and others take to denying the antecedent involves different ways of interpreting arguments of this form to show the valid argument that the author must have meant to present. Interpreting or reconstructing every argument with an invalid form into one that is valid relies on a strong logical assumption that invalid arguments as a whole are illegitimate, an assumption that denies the possibility of a strong inductive argument. Two recent discussions of denying the antecedent offer another approach that challenges this assumption. The first argues that denying the antecedent may be risky but useful where our information resources are limited (Floridi 2009: 322-23). The second argues that when used as a way of expressing dissent denying the antecedent is a legitimate argumentative strategy (Godden and Walton 2004: 219-20). Here one person has used a particular reason $\mathrm{R}$ to support a conclusion $\mathrm{C}$. According to this analysis, while denying the antecedent may not be used to show that $\mathrm{C}$ is false, it may be used to argue that $\mathrm{C}$ is inadmissible on the basis of $\mathrm{R}$, and thus that another reason must be advanced for believing C (Godden and Walton 2004: 233-34).

In this paper, I examine these different ways of approaching denying the antecedent: the first involving various attempts to interpret it or reconstruct it as a valid argument, and the second arguing for its legitimacy in a limited context. Although there are surely examples in which what appears to be denying the antecedent can be interpreted in a way that avoids the fallacy, I will argue that it is improbable that we should always attempt to reconstruct the argument in a way that eliminates the apparent fallacy. Much of the emphasis on this type of reconstruction is based on the assumption that altering the form of the argument significantly improves it, which we will see is not the case. The premises of an argument that denies the antecedent do have inductive strength that undermines a position. I am sympathetic with the positions taken by the second perspective. Floridi's argument demonstrates that with adequate information an argument that denies the antecedent has inductive strength that can be precisely determined. This conclusion supports the view that denying the antecedent can be an effective inductive argument even in contexts where the information resources are limited. Godden and Walton illustrate the legitimacy of denying the antecedent in an argumentative dialogue. In this context it is legitimate to use denying the antecedent as an argument for rejecting the conclusion advanced by a prior argument. I think, 
however, that in light of these arguments and other considerations we can go further and say that denying the antecedent can effectively be used in argumentation to undermine an opponent's position for which plausible reasons have been or may be offered. The premises of an argument that denies the antecedent in this context can have the logical force of an inductive argument, meaning that if the premises are true the conclusion probably follows. In undermining the opponent's position this form of argument provides reasons for believing that the position is false. The upshot of this analysis and argument is a significant revision of the view that denying the antecedent is simply a formal fallacy that should be discarded. Denying the antecedent is a legitimate and effective inductive argument strategy. Before we turn to these arguments let's briefly consider the reasons for classifying denying the antecedent as a formal fallacy and dismissing it as an unacceptable pattern of reasoning.

\section{An invalid form of reasoning}

Logicians classify denying the antecedent as a fallacy because it is an invalid argument form. It has a conditional premise and a premise that denies the antecedent of this conditional, and it concludes with the denial of the consequent. In the most recent edition of their Introduction to Logic, Copi and Cohen give the following example of this pattern of argument:

If Carl embezzled the college funds, then Carl is guilty of a felony.

Carl did not embezzle the college funds.

Therefore Carl is not guilty of a felony. (Copi and Cohen 2009: 300)

This argument is invalid because it is possible for the premises to be true and for the conclusion to be false. Even if Carl did not embezzle the college funds, which would be a felony, it is still possible that he has been selling drugs to undergraduates at a nearby community college, an offense that would make him guilty of a felony. In this case the premises of the argument would be true, but the conclusion false. So the argument is invalid.

The claim that denying the antecedent is a fallacy follows from the view that a fallacious argument is one that seems to be good but is not. This general account of a fallacy, which derives from Hamblin's study, captures both the logical and the psychological problems with fallacies. The premises do not 
provide sufficient evidence to logically support the conclusion, but the argument nevertheless leads someone to believe that the conclusion has been established based on the premises. In short, the reasoning is defective and deceptive (Hamblin 1970: 12). This is basically the argument Govier makes in her account of denying the antecedent. She argues that it is a fallacy because it is invalid but may be mistaken for modus tollens, a valid form of reasoning. Denying the antecedent and affirming the consequent, she says, are "two invalid kinds of arguments that are relatively common and are deceptive because they are so easily confused with modus tollens and modus ponens" (Govier 2001: 290). So an argument that involves denying the antecedent is a fallacy either because the author is trying to deceive us in thinking that it is a good argument or because we are deceived in thinking that the argument is good.

The contentious part of this argument lies somewhere between Govier's comments above that denying the antecedent is "relatively common" and that it is "easily confused" with valid forms of argument. Since it is an invalid form of reasoning, a common approach to the denying the antecedent is to interpret what appears to be fallacious reasoning as some form of valid reasoning.

\section{An uncommon pattern of reasoning}

One of the debated issues in informal logic is whether real arguments commit the fallacies that are named and classified in logic textbooks. The issue then is not whether denying the antecedent is defective and deceptive, but whether anyone actually argues using this pattern of reasoning. Consider the negative political argument against Smith appearing shortly after news of the lies he told about his college career became public:

If Smith were honest then he would be a good candidate for governor.

But he is not honest.

Therefore, he isn't a good candidate for governor.

A student of logic may read the passage and identify this argument as an example of the fallacy of denying the antecedent, based on its form. Unless the argument shows up as an exercise in the fallacies chapter of a logic book, we might question whether the author commits a fallacy in reasoning or means something different from what has been said. The reasoning can be strengthened with the assumption that every good candidate for governor is honest, or the equivalent 
assumption that a candidate who isn't honest isn't a good candidate. Either assumption produces a valid form of reasoning. This approach appears in various attempts to argue generally that genuine fallacies are few and far between, and specifically that denying the antecedent rarely if ever occurs. By interpreting the argument in the correct way, we can see the valid pattern of reasoning that the arguer is employing rather than the fallacy the argument seems to employ.

In "Denying the Antecedent: A Common Fallacy?" Burke argues that virtually all examples of what appear to commit this fallacy can be interpreted in a way that the fallacy is avoided. The example he works with is one of his own concerning capital punishment.

If capital punishment deterred murder, it would be justified. Since capital punishment doesn't deter murder, it isn't justified.

In his view, this argument, like others of the same form, is not an example of denying the antecedent. "It is plausible," he concludes, "to view the passage as consisting of a conditional statement followed by an enthymematic instance of modus ponens" (Burke 1994: 25). Accordingly, the argument contains the unstated premise: if capital punishment doesn't deter murder, then it isn't justified. Burke justifies his reading of the passage by a principle of fairness that of two interpretations of an argument we should not prefer the one that does not involve a fallacy "unless the balance of textual, contextual, and other evidence favors it" (Burke 1994: 24). Since his way of interpreting the argument employs a valid argument form, it is preferable to the argument as it was stated.

Burke recognizes that his argument for introducing an assumption that would provide a valid argument for the conclusion does not by itself absolve the arguer from what appears to be denying the antecedent. How does the conditional that is explicitly stated figure into the passage? He asserts that we cannot accuse the arguer of fallacious reasoning because "there is no adequate reason to regard the conditionals they contain as premises" (Burke 1994: 24, italics in text). In his view the conditional statement that is explicitly stated is not a premise of the argument at all; it functions rhetorically to defuse resistance from the audience. It has the role, he says, "of clarifying the nature of the arguer's objection to capital punishment, of making clear that the arguer opposes capital punishment only because the arguer believes it doesn't deter murder" (Burke 1994: 25). This explanation alone is insufficient for two reasons. First, since the text contains the conditional, 


\section{Mark Stone}

there is adequate textual evidence for regarding the conditional as part of the argument. Second, even if the conditional has the rhetorical purpose Burke suggests, it could still be a premise in the argument; these possibilities are not mutually exclusive. In commenting on Burke's strategy with respect to this and other examples, Godden and Walton make the important larger point that "there seems to be plenty of textual evidence to suggest that the arguers in these cases are asserting the stated conditionals, while the only evidence to suggest that they are asserting the inverse conditional is provided by a normatively driven principle of charity" (Godden and Walton 2004: 227, italics in text). The presupposition behind the application of such a principle is that the interpretation or reconstruction of the argument into one that is valid makes the argument better. We shall see that this presupposition is problematic, however, because the considerations that weaken denying the antecedent have a similar effect on the reconstructed arguments.

One way of mending this interpretive approach that avoids the problem of dealing with the conditional statement is to argue that we should interpret the conditional statement itself as a biconditional statement. This is the general approach that Adler considers in "Fallacies and Alternative Interpretations." He begins by examining one of the purported examples of denying the antecedent drawn from John 8:47 that George first called attention to (George 1983: 323). In the King James translation of the Bible, which George uses, this passage reads:

He that is of God heareth God's words: ye therefore hear them not, because ye are not of God.

For George the form of the argument obviously fits the fallacy of denying the antecedent. Adler observes though that "an alternative interpretation of this argument is readily found. Perhaps, the initial statement is not to be read as a conditional, but as a bi-conditional implying that 'He that heareth God's words is of God"" (Adler 1994: 271, italics in text). The argument in the passage is then valid.

Although this alternative interpretation leads to a valid argument, it does not eliminate the possibility or even the likelihood that the argument involves fallacious reasoning. Adler argues that generating a non-fallacious interpretation by introducing more claims than are stated in the original passage has its own problems unless the passage contains evidence that would warrant these additional claims. In other words, finding a way to avoid reading the passage as committing a fallacy is not by itself a justification for these claims. He maintains that "it is no genuine improvement in an argument to secure a better 
relation between premises and conclusion by introducing any assumption ... that is unsupported" (Adler 1994: 275, italics in text). This is the problem with the proposed interpretation of John 8:47. If the arguer meant the conditional statement to be understood as a bi-conditional, the form of the argument would then be valid. The arguer's implicit assertion of its converse, however, would be unwarranted without further evidence because a conditional does not imply its converse.

Adler is specifically concerned with the claim that an attribution of a fallacy is an attribution of fallacious reasoning. "The attribution," he continues, "must then correspond to reasoning in the mind of the person criticized" (Adler 1994: 277). As a result, the non-fallacious alternative does not necessarily overrule the fallacy attribution. Adler makes his point with respect to the child's argument:

If I don't do my homework, my dad won't let me play basketball. I'll finish, so then he must let me go. (Adler 1994: 277)

Although it looks like the speaker argues by denying the antecedent, the alternative interpretation is that the conditional is really a bi-conditional. In this argument, Adler urges us to assume that the child intended the non-fallacious argument. It still does not follow that a fallacy has not been committed. Adler asserts that

My claim is that there need be no rivalry between the view that the child meant his conditional as a biconditional, and that his reasoning involved a fallacious reversal of the conditional. For the child's meaning by that conditional a bi-conditional, is itself plausibly due to his treating the conditional as reversible. (Adler 1994: 277)

In other words, the alternative does not decisively overrule the possibility that the child has reasoned fallaciously. Suppose that it is true that people generally treat conditionals as biconditionals, so that whenever we find an example of denying the antecedent we interpret the conditional premise as a biconditional making the argument valid. This still does not make their reasoning more rational unless there is warrant for supposing that both the conditional and its converse are true. The other possibility is that they reason fallaciously that the conditional implies its converse.

One solution to this problem is to interpret the argument in a way that avoids denying the antecedent and illicitly assuming the converse of the conditional premise. David Hitchcock offers 


\section{Mark Stone}

this type of interpretation of the argumentative passage in John 8:47 in which Jesus says: "He that is of God heareth God's words: ye therefore hear them not, because ye are not of God." Hitchcock follows Burke in treating this passage as a predicatelogic analogue to denying the antecedent. "For every $\mathrm{x}$, if $\mathrm{x}$ is $\mathrm{G}$, then $\mathrm{x}$ is $\mathrm{H}$. And a is not G. So a is not H" (Hitchcock 1995: 299). He also like Burke believes that it is given that the audience to whom Jesus is speaking does not hear the words of God. So what is happening in the passage is not an argument that the audience does not hear the words of God, but instead an explanation of the fact that they do not hear God's words. In his view the conditional statement is a premise that supports an explanation in the following argument:

Premise: He who is from God hears the words of God.

Conclusion: You do not hear because you are not from God. (Hitchcock 1995: 299)

It is clear in his view that both speaker and audience agree that they do not hear the words of God, so it follows validly that they are not from God. The form of the reasoning is "Every G is H. a is not $\mathrm{H}$. Therefore, a is not $\mathrm{H}$ because a is not G" (Hitchcock 1995: 299). Here "a is not $H$ " is a premise in the argument and with the other premise "Every $\mathrm{G}$ is $\mathrm{H}$ " entails the subsidiary conclusion "a is not G" by modus tollens. The conclusion of argument " $\mathrm{a}$ is not $\mathrm{H}$ because a is not $\mathrm{G}$ " explains why a is not $\mathrm{H}$. The reasoning, Hitchcock admits, is not valid unless we suppose that $G$ is a sufficient causal condition. "This form of argument is valid," he maintains, "for instances where G is a sufficient causal condition for $\mathrm{H}$, and only for such instances" (Hitchcock 1995: 299). For example, turning the light switch on is a sufficient causal condition for the light to come on. Thus, from the fact that the light is not on, we can validly conclude that the light is not on because no one turned the light switch on. So what looks like a fallacious argument denying the antecedent is a valid argument from a general causal claim to a particular causal claim.

Though this interpretation of the passage is possible, the complexity of it alone makes it difficult to conclude that it is plausible. The argument also depends on the claim that "it is already known to both him and his audience that they do not 'hear' (i.e. believe) him" (Hitchcock 1995: 299). This assertion, however, depends upon claiming that "believe" (pisteuete) in verse 45 means the same as "hear" (akouete) in verse 47, a claim for which no evidence is offered. This interpretation which involves an argument that is formally invalid seems inferior to the previous one whose form is valid. Finally, following Adler 
we might claim that it is just as plausible to suppose that the arguer reasons fallaciously as that "it is natural to take it [being from God] as a sufficient causal condition" (Hitchcock 1995: $300)$. In light of these problems, it is clear that this interpretive approach does not offer a way to dismiss all or even most cases of what appears to be denying the antecedent.

The preceding interpretations require us to impute assumptions to the arguer that may or may not be justified, and that do not necessarily rule out fallacious reasoning on the part of the arguer. Another interpretive approach that relies on conversational implicature holds that the required premises are already pragmatically implied by the argument, so we do not need to introduce additional assumptions.

In "Pragmatic Considerations in the Interpretation of Denying the Antecedent," Moldovan uses Grice's notion of conversational implicature to analyze the conditional statements of these arguments. The focus in this analysis falls on the distinction between what is said by an argument and what is meant by it. What is said by an argument is the explicit statements that can be identified as the premises and conclusion in reference to argument indicator words and meta-discourse in the passage. What is meant by an argument takes into consideration presuppositions and implicatures of what is said for a full account of the argument. Whereas the previous interpretive strategy called attention to the need for a reader or hearer to interpret the conditional as a bi-conditional in order to recognize a valid pattern of reasoning in the argumentative passage, this strategy relies on the pragmatic phenomenon of conditional perfection. In Moldovan's words, conditional perfection "consists in treating an utterance of 'If $p$ then $q$ ' as expressing not only that $\mathrm{p}$ is a sufficient condition for $\mathrm{q}$, but also that it is a necessary condition." (Moldovan 2009: 313) This approach has the advantage over the prior interpretive approach in that no additional assumption is being made that needs justification beyond the assertion of the conditional, which invites the inference to its converse. This inference is instead a linguistic phenomenon that is understood by competent language users. "The phenomenon," Moldovan explains, "is usually treated as involving pragmatic strengthening of the content of the utterance, in the sense that the invited inference is to be explained as an implicature" (Moldovan 2009: 313-14, italics in text).

Moldovan uses the homework and basketball example to illustrate this way of understanding what may look like a case of denying the antecedent. Here the child presents the following argument to her friend: 


\section{Mark Stone}

If I finish my homework, my dad will let me play basketball. But I will not finish it today; it's just too difficult. So, he will not let me play basketball today. (Moldovan 2009: 318)

The relevant implicatures are that there are no other sufficient conditions that must be satisfied before the father will permit his child to play basketball and that finishing the homework is also a necessary condition. In Grice's account of implicature a maxim of quantity and a maxim of relations function in pragmatic contexts such as this one; the speaker conveys only as much information as is needed to be understood and only information that is relevant to the conclusion (Grice 1989: 2627). If there were other sufficient conditions they would have been mentioned, and if finishing the homework were not a necessary condition this would have been mentioned. So for these pragmatic reasons it is reasonable to think the converse of the conditional statement is part of what the argument means. Moldovan concludes: "It is rational to derive the implicature that the inverse of the conditional also holds. Therefore, the father's utterance conveys a necessary condition for the truth of the consequent, not merely a sufficient one" (Moldovan 2009: 319). So what appears to be a case of denying the antecedent is instead a valid argument.

Moldovan's approach calls attention to instances in which an argument with the form of denying the antecedent can be interpreted as a valid argument because of pragmatic considerations. What is said as a conditional can be reconstructed through conversational implicature as a biconditional. Other interpretive approaches suggest that we make this assumption for rational considerations. We now have a valid argument whether it is exactly what the author intended or what we can rationally derive from what the author said. If there is no evidence that would warrant the assertion of a bi-conditional above what may exist for the conditional, we can ask whether eliminating the formal fallacy in favor of the valid argument makes it more rational. If what makes an argument rational involves the evidence that may be presented in support of or in opposition to it, then strengthening the argument in the manner we have been considering does not make the argument any more rational. Consider the argument introduced earlier as an example of denying the antecedent:

If Smith were honest then he would be a good candidate for governor.

But he is not honest.

Therefore, he isn't a good candidate for governor. 
Its weakness as an argument stems from the possibility that there are other reasons for judging that Smith would be a good candidate, his economic expertise or his ability to work with members of both political parties. The approaches we have considered so far argue correctly that strengthening the premise so that honesty is a necessary condition of his being a good candidate would give us a valid argument:

Smith is a good candidate for governor if and only if he is honest.

He is not honest.

Therefore, he isn't a good candidate for governor.

Since this argument is now valid and we cannot criticize the inference, any problems with the argument revert to the truth or falsity of the premises. To show that this valid argument is weak we can argue that there are other reasons that would make Smith a good candidate, that it is not necessarily true that he is a good candidate only if he is honest. Here the evidential considerations that reveal the weakness of this reconstructed argument are the same used to demonstrate the weakness of the invalid argument denying the antecedent.

If this reconstructed argument is weakened by the same considerations that are used to criticize denying the antecedent as an invalid argument, strengthening the conditional does not do the logical work that these interpreters think that it does. Though some cases of denying the antecedent are likely to be instances in which the arguer means for us to understand her conditional as a bi-conditional, the argument that we should invariably interpret instances of denying the antecedent this way is weak. Adler makes the point that securing a better relation between premises and conclusion by introducing an unwarranted assumption does not genuinely improve the argument (Adler 1994: 275). The point here is similar. Since the reconstructed valid argument may be criticized for the same reasons as the argument denying the antecedent, interpreting the argument in this way does not genuinely improve it. So strengthening the conditional in arguments that deny the antecedent does not do the logical work that these interpreters assume that it does. Since the rationale for interpreting denying the antecedent as a form of valid reasoning is questionable, some occurrences of this formal fallacy evidently do occur. A more interesting question is whether any of these occurrences are legitimate. 


\section{Denying the antecedent as a legitimate argument strategy}

Although most writers argue that denying the antecedent when understood exclusively as a formal fallacy is by definition an illegitimate argument strategy, two sources have recognized that it has legitimate uses as long as we accept certain limitations: since it is not a valid form of reasoning, it cannot be used to establish a conclusion with certainty. The first argues that denying the antecedent is useful as a shortcut in probabilistic reasoning to make a prediction. The second argues that it is useful as a move in an argumentative dialogue.

In "Logical Fallacies as Informational Shortcuts" Floridi uses a Bayesian analysis to argue that denying the antecedent and affirming the consequent "are not just basic and simple errors, which prove human irrationality, but rather informational shortcuts, which may provide a quick and dirty way of extracting useful information from the environment" (Floridi 2009: 317). Let's consider an example in order to follow the details of Floridi's argument. Since he bases his conclusion about denying the antecedent on an example that begins with the fallacy of affirming the consequent we will do the same here.

Suppose that the cyclists on Team A are going to be tested for performance enhancing drugs, and of the nine riders on the team two have been using drugs. The independent testing company that has been hired indicates that its testing procedures are $95 \%$ accurate for athletes who are using banned substances. The company further reveals that the false positive rate of the rate of athletes who are not using banned substances, but who nevertheless test positive is $5 \%$. If my favorite rider tests positive for drugs, though I may be skeptical, I am likely to reason as follows:

If he is using a banned substance, then he would test positive.

He tested positive.

Therefore, he has been using a banned substance.

Since we know that some members of the team are using drugs and there is a false positive rate for the tests, we can use Bayes' theorem to calculate the probability that he used a banned substance $(u)$ given that he tested positive $(p)$ or $P(u / p)$. The probability that he would test positive given that he used a banned substance $-\mathrm{P}(\mathrm{p} / \mathrm{u})-$ is .95 , and the probability that he is using a banned substance $-\mathrm{P}(\mathrm{u})-$ is $2 / 9$, or .22 . The probability that he tests positive even though he is not using a banned substance $-\mathrm{P}\left(\mathrm{p} / \mathrm{u}^{\prime}\right)-$ is the false positive rate of .05 , and the 
probability that he is not using a banned substance $-\mathrm{P}\left(\mathrm{u}^{\prime}\right)-$ is 7/9 or .78. Applying Bayes' theorem to determine the probability that he has been using a banned substance given that he tested positive yields:

$$
\mathrm{P}(\mathrm{u} / \mathrm{p})=\frac{\mathrm{P}(\mathrm{p} / \mathrm{u}) * \mathrm{P}(\mathrm{p})}{\mathrm{P}(\mathrm{p} / \mathrm{u}) * \mathrm{P}(\mathrm{p})+\mathrm{P}\left(\mathrm{p} / \mathrm{u}^{\prime}\right) * \mathrm{P}\left(\mathrm{u}^{\prime}\right)}=\frac{95.22}{.95 * .22+.05 * .78}=.84
$$

The inference of the argument above, an example of affirming the consequent, is not valid because it is possible for the premises to be true and the conclusion to be false. So I can still hold out hope that my favorite rider is clean. It is, nevertheless, highly probable that the conclusion follows and he is not. With the information we have, the probability that a rider is using a banned substance given that he tested positive is .84 . Since generally speaking the false positive rate of athlete drug testing is low, someone who reasons in this way may be wrong but is most likely correct. Floridi observes that the case for denying the antecedent is analogous.

With respect to the same example I might argue with respect to another rider on Team A as follows:

If he were using a banned substance, then he would test positive.

But he is not using a banned substance.

Therefore, he will test negative.

In our example, since the probability that he will test positive even though he is not using $\operatorname{drugs}-\mathrm{P}\left(\mathrm{p} / \mathrm{u}^{\prime}\right)$ - is .05 , the probability he will test negative given that he is not using performance enhancing drugs- $\mathrm{P}\left(\mathrm{p}^{\prime} / \mathrm{u}^{\prime}\right)$ - is .95 . So if the evidence I have that he is not using any performance enhancing drugs is reliable, then the conclusion of the argument has a high probability of being true if the premises are. The argument is invalid because there is the possibility that the premises are true and the conclusion false. But we know here that is it a slim one, .05. So, despite the invalid form, it is a strong inductive argument.

A final point of this Bayesian analysis relates to what happens in the event that there are no false positives. In this case the probability that a rider who tested positive used drugs is one, which means that conditional in both of our arguments is actually the bi-conditional, "a rider tests positive for a banned substance if and only if he has been using one." The logical consequence of this change is that both arguments become valid. The premise that the rider is not using a banned substance 
combined with this bi-conditional premise allows us to conclude validly that he will not test positive for it. Floridi summarizes his results as follows:

DA [denying the antecedent] and AC [affirming the consequent] assume (and here is the logical mistake) that there are no false positives (double implication), or that, if there are, they are so improbable as to be disregardable (degraded Bayes' theorem). So DA and AC are Bayesian "quick and dirty" informational shortcuts. (Floridi 2009: 322)

Our example above has all the information that we need to determine probabilities needed to make reasonably good arguments that use these invalid forms. But generally we do not have sufficient information about whether there are false positives or not. So in using these invalid forms we are in effect betting that there are no false positives or that they are negligible. "The bet might be risky (we might be wrong)," Floridi concludes, "but it often pays back handsomely in terms of lower amount of informational resources needed to reach a conclusion" (Floridi 2009: 322-3).

Although Floridi recognizes the utility of denying the antecedent as an informational shortcut, he still dismisses it in the context of argumentation. It is "still a disaster," he says, "if our goal is to win an argument, because our opponent will not have to be too smart to provide plenty of counterarguments" (Floridi 2009: 324). This conclusion seems puzzling in light of his overall argument. Consider again the example of denying the antecedent offered by Copi and Cohen about embezzlement:

If Carl embezzled the college funds, then Carl is guilty of a felony.

Carl did not embezzle the college funds.

Therefore Carl is not guilty of a felony.

(Copi and Cohen 2009: 300)

Although this is not the type of case for which we might get the probabilities needed for a Bayesian analysis, we might still say that the argument was inductively strong because of the unlikelihood that Carl has committed some other felony. It is still possible that he is guilty of a felony, but not likely. Here the goal is to win the argument regarding whether Carl is guilty of a felony or not. The opponent has probably already made the valid modus ponens argument:

If Carl embezzled the college funds, then Carl is guilty of a felony. 
Carl did embezzle the college funds.

Therefore Carl is guilty of a felony.

For the opponent to respond to our argument denying the antecedent by providing counter arguments that Carl might be selling drugs in the next county or that he might be guilty of a felony DUI is easy but irrelevant. If the argument denying the antecedent includes reliable evidence that Carl did not embezzle the funds, then the argument goes to establish that Carl is not guilty of a felony in light of the limited probability that Carl is guilty of some other felony. So the Bayesian analysis supports the view that denying the antecedent can be an effective inductive argument strategy, especially in response to another argument.

Godden and Walton have argued that denying the antecedent may be legitimate in response to another argument. There are two parts to their argument. The first part involves taking a broader view of argument and understanding denying the antecedent as an argument strategy. Non-fallacious uses of this strategy, they contend, "require that denying the antecedent be viewed dialectically, as a move made within an argumentative dialogue" (Godden and Walton 2004: 220). Their interpretation then depends on what they call a pragmatic theory of argument. The second part of their argument concerns establishing a way of referring to the value of a legitimate use of denying the antecedent. Such arguments are not valid, but they're not all bad either. In their view, the person who argues with this argument strategy is not attempting to conclude anything about the truth or falsity of a claim. The arguer is instead showing that the claim is unacceptable for the initial reason given and should not be admitted as a commitment in the argumentative dialogue on this basis. "The claim is not shown to be false (whereby the negation of the claim would be shown to be admissible)," they explain, "rather the claim is shown to be inadmissible" (Godden and Walton 2004: 232). In examining their argument more carefully, I would like to show that the dialectical context they present for looking at denying the antecedent can be understood more broadly and that they construe the legitimacy of this argument strategy too narrowly.

The context in which Godden and Walton argue that denying the antecedent has a legitimate use is an argumentative dialogue. This dialogue involves a proponent (Pro) and a respondent (Resp). Suppose that Pro has argued for the claim $\mathrm{C}$ by offering $\mathrm{A}$ as a reason. Pro believes that $\mathrm{A}$ is true and that $\mathrm{A}$ implies $C$, and validly concludes that $C$ is true. Resp may dissent with the argument that Pro has offered in several ways, one of which is by denying the antecedent of the conditional offered in 


\section{Mark Stone}

Pro's argument. Resp may agree that A implies C, but claim that $\mathrm{A}$ is false as a way of dissenting from Pro's conclusion C. In dissenting Resp is not offering an argument for the falsity of the conclusion $\mathrm{C}$, but instead arguing that we should not accept $\mathrm{C}$ on the basis of A. They summarize this strategy as follows:

\footnotetext{
Resp does not deny the antecedent $\mathrm{A}$ in an attempt to establish the falsity of $\mathrm{C}$; indeed the strategy does not seek to establish any claim (i.e., commitment) in the argumentative discussion whatsoever. Rather, the move is made in an attempt to demonstrate that $\mathrm{C}$ has not been established, and hence that it cannot be admitted into the argumentative discussion as a commitment. (Godden and Walton 2004: 231)
}

In their view denying the antecedent is a legitimate argument strategy when it is used in an argumentative discussion to dissent from a claim. Denying the antecedent, however, is not successful if it is used to establish some claim.

Godden and Walton summarize the two consequences of legitimate uses of denying the antecedent as follows:

On our model, there are two. The first is to defeasibly show that a claim has not been established as acceptable. The second argument effect is to shift the burden of proof in regards to a claim at issue back to the proponent of that claim. (Godden and Walton 2004: 233)

They further explain the first consequence by noting that "the conclusion of the counter-argument is not that we should accept not $C$, but rather that we should not accept $C$ for the reasons given in the initial conditional argument." (Godden and Walton 2004: 239, emphasis in text)

As Godden and Walton argue, viewing an argument in its dialectical context is a crucial aspect of evaluating it. I definitely agree with them that an argument in which the arguer denies the antecedent can be legitimate as a strategy for responding to a previous argument and undercutting the evidence that has been offered for an earlier conclusion. The context for this type of argumentative discourse can be a dialogue between two persons as they suggest, but it could just as well occur as part of a reader's response to an argument in a text, or a writer's attempt to diffuse reasons that an audience might offer in support of a position contrary to her own that have not yet been actually presented. In fact, what makes the argumentative context one in which denying the antecedent might be an effective argument to reject a position appears to be the same one in which a modus ponens argument would be an effective means of supporting it. 
If denying the antecedent can be a legitimate argumentative strategy to reject a position, then it follows that it can be used to establish the improbability of a position. On the one hand, Godden and Walton seem to agree that the dialectical model of argumentation they advocate might allow a proponent to use denying the antecedent in this way. "Since it is the job of the proponent to establish a claim," they argue, "and no positive claim is established by a legitimate use of DA, it would be a highly unusual circumstance in which a proponent would ever find a use for such an argumentative strategy." (Godden and Walton 2004: 239) On the other, they deny that the argument has the force of rejecting a position: "Legitimate uses of DA only really establish that a claim has not been established." (Godden and Walton 2004: 239)

Whereas they maintain that the force of this type of argument is only that we should not accept the conclusion $C$ for the reasons given in the initial conditional argument, I think its force is that we should probably accept not $C$, that is, we should probably reject $\mathrm{C}$. In other words, I think denying the antecedent has inductive strength. This is the point at which I believe one can make a stronger case for the effectiveness of denying the antecedent in argumentation.

\section{Denying the antecedent as an effective inductive argument strategy}

We have seen reasons for agreeing that denying the antecedent is a legitimate argument strategy as a way of responding to an argument for a claim that one disagrees with. The minimum requirement for this strategy to work is that the argument one is responding to involve a conditional claim that will serve as the first premise of denying the antecedent. We might consider Burke's example again in this respect. Someone can certainly make the following argument in favor of capital punishment:

If capital punishment deters murder, then it is justified.

Capital punishment deters murder.

Therefore, it is justified.

Since this is a plausible way to argue for capital punishment, the corresponding argument that denies the antecedent of this conditional can be a legitimate argumentative strategy to undermine the position that capital punishment is justified. So the following argument can be a legitimate part of 
an argumentative discourse seeking to show that capital punishment is unjustified:

If capital punishment deterred murder, then it would be justified.

Capital punishment does not deter murder.

Therefore, it is not justified.

It is not necessary, of course, for the original argument to be in the form of modus ponens in order to use denying the antecedent as a legitimate response. For example, the original argument could simply be expressed "Capital punishment deters murder, therefore it is justified." Ryle observes, correctly I think, that although the argument is not equivalent to a conditional, what makes the argument work is its dependence on the truth of the conditional "if capital punishment deters murder, then it is justified" (Ryle 1971: 237-41). In general we can strengthen any argument of the form "P, therefore Q" to make it valid by reformulating it as an argument using modus ponens. So denying the antecedent would also be a legitimate response to any argument has been expressed or might be expressed in the form "P, therefore Q."

Godden and Walton are correct that denying the antecedent above shows that we cannot accept that capital punishment is justified for the reason that has been offered-it deters murder. The question is whether this is the only logical consequence we can draw. In their view it does not establish that capital punishment is unjustified. Since it is not a valid argument we would agree that it does not establish conclusively that capital punishment is unjustified. Does it establish that capital punishment is probably not justified? In other words, if $\mathrm{C}$ is the proposition that capital punishment is justified, does it provide us with reasons to accept not C? I think that it does.

One of the first ways to see that it does is to return to Burke's way of amending the argument by introducing an additional premise that would make the argument valid. This strategy would provide the necessary support that other things being equal (for example, reliable evidence that capital punishment did not deter murder) would make the argument credible and the conclusion well supported by the premises. The revised argument with the assumed premise in brackets reads:

If capital punishment deterred murder, then it would be justified.

Capital punishment does not deter murder.

[If capital punishment does not deter murder, then it is not justified.] 
Therefore, it is not justified.

Although this change makes the argument formally valid, it is important to remember that validity is itself a conditional: if the premises are true, then the conclusion must be true. In this case, the argument's strength would depend upon showing the truth of the bracketed premise. As we will see, however, the same considerations which may be raised to challenge denying the antecedent apply here, too. Someone may argue that capital punishment is justified for retributive reasons. Punishment is an appropriate response to a crime that has been committed, not a means of preventing future crime. With the valid argument this challenge, if good, means that the argument is weak because the assumed premise is false. With denying the antecedent, it means that the argument is weak because it has clearly been shown that the premises may be true but the conclusion false. On the other hand, if the challenge fails, Burke and others would presumably argue that the valid argument establishes conclusively that capital punishment is not justified. I would argue that if the challenge fails, the argumentative force of denying the antecedent becomes apparent; it is inductively strong. The argument without the bracketed premise establishes that capital punishment is probably not justified. The argument that denies the antecedent is defeasible, but the argument that Burke proposes is weakened by the same evidential considerations. If these considerations are true, they show the weakness of the inductive inference of the former argument, but they also show that the bracketed premise of the latter argument is false.

The argument above applies similarly to attempts to fix an argument that denies the antecedent by interpreting the conditional premise as a bi-conditional or suggesting that the converse of the premise is part of the argument in some other way. It appears that the thinking behind this sort of rational reconstruction is that the argument is better for it. The premise that Burke proposes is logically equivalent to the converse of the conditional premise of the argument, if capital punishment is justified then it deters murder. The argument that capital punishment is justified for retributive reasons, which is a potential defeater for denying the antecedent, would also mean that deterring murder is not a necessary condition for justifying capital punishment. Again, although the strengthened premise would make the argument formally valid, it would not significantly strengthen the original argument. Evidence that shows the weakness of the inductive inference of denying the antecedent also shows that the bi-conditional premise of the valid argument is false. 


\section{Mark Stone}

One might naturally object that the valid argument is a genuine improvement over the original argument because it is valid, and valid arguments are more logically persuasive than invalid ones. I would agree that all things being equal valid argument are preferable to invalid ones because that are deductively conclusive. Inductive arguments can also be logically persuasive even though they are invalid. With a good inductive argument the conclusion is probably true if the premises are. In this example, with compelling evidence that deterring murder is a necessary condition for justifying capital punishment, an arguer should present the valid argument that since it does not deter murder capital punishment is not justified. In the absence of such evidence, someone who believes that deterring murder is a sufficient condition for justifying capital punishment and who has evidence that it does not deter murder can make an inductive argument in the form of denying the antecedent that capital punishment is probably not justified. This argument has inductive strength. How strong it is depends on how successful other arguments to justify capital punishment are. If the retributive argument suggested earlier is unsuccessful, then the inductive argument denying the antecedent is accordingly stronger.

Floridi's analysis of denying the antecedent provides a second way of seeing that such arguments do more than establish that someone else has not established a claim. His argument shows that where there is sufficient information for a Bayesian analysis, the probability of the conclusion of denying the antecedent can be specified precisely so that we can determine its inductive strength. His analysis also suggests that this type of analysis can be applied to arguments where such precise information is lacking. The argument that we considered earlier in the cycling scenario demonstrates this first point:

If a cyclist were using a banned substance, then he would test positive.

But he is not using a banned substance.

Therefore, he will test negative.

Knowledge that the rate of false positives for the drug testing procedures being used is .05 , then the probability that the conclusion of this argument is true if the premises are true is .95 or $95 \%$. Since there is a $5 \%$ chance that he will test positive even if he is not using a banned substance, we should amend the conclusion to read "he will probably test negative." The argument establishes a positive conclusion even though it does not do so conclusively. 
In this argument we have information about the probability of a false positive on the drug testing procedures. The lower the expectation is of a false positive, the more probable is the conclusion. In cases where we cannot determine with exactness what the probability of a conditional premise is or what the chance of a false positive is, it is still reasonable to suppose that arguments of the same form would have some probative value. Consider one of Floridi's examples of a student reasoning about her chances of success on a test. Her teacher has assured her that if she does not study enough, then she will fail the test. Maggie the student reasons as follows:

If I do not study enough, then I will fail the test.

I am going to study enough.

Therefore, I will pass the test.

Her argument is an example of denying the antecedent. Since some students do study more than enough and still fail the test, the conclusion does not follow conclusively. But since on average students who study some pass the test, her reasoning provides support for the conclusion. Even though there is not an accurate measure of the percentage of students who study for a test in this class but fail, it is still reasonable for Maggie to draw the conclusion she does. In other words, the argument has inductive strength. It is true enough that her roommate can easily point out that it is still possible that she is going to fail or mention that she knew someone the last semester who studied a lot for the test and still failed. The first consideration shows only that the argument is not deductively conclusive and the second may show that the argument is not as strong as Maggie thought. But it still has inductive strength.

Floridi might object that these examples demonstrate that denying the antecedent has inductive strength as an "inference to best prediction," but they do not address his assertion that if the goal is to win an argument then denying the antecedent is a disaster (Floridi 2009: 324). In a dialectical context, however, we have seen that denying the antecedent is a legitimate way of dissenting from an opponent's position and can be used to establish that this position is inadmissible for the reasons that have so far been offered for it. Does Floridi's argument give us any grounds for the further conclusion that denying the antecedent is an argument form that has inductive strength? I think so. The examples of denying the antecedent used to argue that capital punishment is not justified and that Carl is not guilty of a felony are not arguments to the best prediction. But in both there are considerations analogous to the false positives in Floridi's analysis that lend inductive strength to these 


\section{Mark Stone}

arguments. The conclusion of the argument that capital punishment is not justified is strengthened by the likelihood that other justifications for capital punishment are unsuccessful. The conclusion of the argument that Carl is not guilty of a felony is strengthened by unlikelihood that he has committed some other felony. The arguments do involve risk because the conclusions allow for the possibility that the premises are true but the conclusion false. But in the absence of evidence that these possibilities were likely, denying the antecedent has inductive rewards.

A third reason for believing that denying the antecedent has a legitimate role in establishing that a position is improbable draws on the connection between evidence and beliefs. The credibility of one of our beliefs depends on the evidence that we have to support it. Let's return to the claim in my original example that Smith would be a good candidate for governor. Suppose that I believe this because he is honest, he has strong family values, he is fiscally responsible, and he has a history of service to the community. These beliefs form my evidence base for the further belief that he would be a good candidate. If asked I would say that my belief he would be a good candidate for governor is highly probable based on the evidence I have. I could certainly argue for this claim as follows:

If Smith is honest and has strong family values and has served the community, then he is a good candidate for governor.

He is honest and has strong family values and has served the community.

Therefore, he is a good candidate for governor.

If I learn from a credible source that he has a distinguished military service record, I will add this to the overall evidence. As a consequence, my belief that he would be a good candidate becomes more probable with the inclusion of this new evidence. Because of the modus ponens form of the previous argument we might say that it establishes conclusively that Smith is a good candidate for governor. If the premises are true then the conclusion must follow. But from an epistemic point of view, in relationship to the body of evidence for it, the claim is probable. The probability that one of my beliefs is true is based on the body of evidence that I have to support it. Notice, furthermore, that it is made more probable by additional evidence. In the same way in which adding true beliefs makes the claim they support more probable subtracting beliefs that have been found false makes the claim less probable in relationship to the overall body of evidence. If it comes to light that Smith is not honest, 
then the claim that he would be a good candidate for governor becomes less probable.

Suppose that in light of the evidence for Smith's dishonesty a pundit presents the following argument in an editorial in an effort to sway Smith's supporters to another candidate:
If Smith were honest then he would be a good candidate for governor.
But he is not honest.
Therefore, he probably isn't a good candidate for governor.

This argument denying the antecedent captures the way in which the new evidence undermines the body of evidence on which the belief that Smith is a good candidate. To reflect the inductive nature of the reasoning the conclusion includes the word "probably." The argument accordingly provides reasons for believing that he is not a good candidate. Such an argument clearly does, as Godden and Walton have argued, indicate that honesty is no longer a good reason for supporting Smith as a candidate. But in light of the way in which a body of evidence makes the claims based on that evidence more or less probable, the argument does more. It provides reasons that make it more probable that Smith is not a good candidate. The foundational metaphor that has been used in epistemology seems applicable here. If part of the foundation on which a belief is based becomes suspect, the belief itself has been partially undermined. So denying the antecedent is an effective argument strategy because it does provide reasons for rejecting a position. It lends support to believing that the original claim, in this case that Smith would be a good governor, is false.

Though denying the antecedent employs an invalid argument form, these considerations indicate that it can be both a legitimate and logically effective argument strategy because arguments denying the antecedent have inductive strength. Examining the attempts to improve these arguments with additional premises that make them valid demonstrates that denying the antecedent though defeasible has significant argumentative force. For the improved valid arguments are subject to the same defeaters as denying the antecedent and are therefore no stronger argumentatively. With sufficient information about the probability of the conditional premise and the probability of false positives, the probability that the conclusion of an argument that denies the antecedent can be determined precisely. So these arguments clearly have inductive strength. By analogy arguments where we cannot assign probabilities but where there is some chance of the equivalent of 
false positives also have inductive strength. From an epistemic point of few, it is reasonable to conclude that denying the antecedent has inductive strength. It captures the way in which diminishing the body of evidence on which a claim is based makes that claim less probable. Where $\mathrm{C}$ is a claim which has been supported by some reasons, the force of denying the antecedent is not only that we should not accept the conclusion $C$ for the reasons given in the initial argument, but that we should probably accept not $C$. The logical effectiveness of denying the antecedent as an argument strategy can be further confirmed by examples.

\section{Two significant examples of denying the antecedent}

In this section I consider two examples in which philosophers use denying the antecedent as an argument strategy. The first is from Rachels's discussion of the way in which he believes Darwinism undermines the idea of moral dignity, and the second comes from Locke's refutation of the notion of innate principles. Both examples clearly fit the argumentative context in which we have established that denying the antecedent has a legitimate role, and both demonstrate the effectiveness it has as an argument strategy.

In his book Created from Animals: the Moral Implications of Darwinism, Rachels argues that Darwinism undermines traditional morality by undermining the idea of human dignity. Part of what is interesting about his argument is that he explicitly makes the point that undermining the support of a position is not a proof that the position is false. Taking away the support for a position makes it less probable in light of the overall evidence, that is, it makes the denial of this position more probable. He presents his argument as a response to the argument that since human beings are created in the image of God and since human beings are uniquely rational, "human life has a special, unique value" (Rachels 1990: 4). This latter claim that human life has a special, unique value captures the idea of human dignity. "Darwin's theory," he observes, "does not entail that the idea of human dignity is false. ... Darwinism does, however, undermine the traditional doctrine ... by taking away its support” (Rachels 1990: 4-5, italics in text).

Rachels' argument that Darwinism undermines the idea of human dignity attacks two main doctrines that are presented as support for the idea that human beings have moral dignity: (1) the view that humans are made in the image of God and (2) the view that human beings are uniquely rational. The way he 
applies this reasoning to his main argument is worth quoting in full:

\begin{abstract}
We are now in a position to explain how Darwinism might undermine traditional morality. The claim that Darwinism undermines traditional morality is not the claim that it entails that the doctrine of human dignity is false. It is, instead, the claim that Darwinism provides reason for doubting the truth of the considerations that support the doctrine. From a Darwinian perspective, both the image of God thesis and the rationality thesis are suspect. Moreover, there are good Darwinian reasons for thinking it unlikely that any other support for human dignity can be found. Thus, Darwinism furnishes the "new information" that undermines human dignity by taking away its support. (Rachels 1990: 97-98)
\end{abstract}

The arguments that Rachels attacks depend on two conditionals: "If human beings are created in the image of God, then human beings have moral dignity" and "If human beings are uniquely rational, then human beings have moral dignity." The arguments that Rachels uses to undermine the notion of human dignity involve denying the antecedent of these conditionals. These arguments are, first:

If human beings are created in the image of God, then human beings have moral dignity.

But human beings are not created in the image of God (as Darwinism has shown).

Therefore, probably human beings do not have moral dignity.

And, second:

If human beings are uniquely rational, then human beings have moral dignity.

But human beings are not uniquely rational (as Darwinism has shown).

Therefore, probably human beings do not have moral dignity.

So undermining the support for the doctrine of human dignity makes the claim improbable. It is also important to observe that Rachels explicitly rejects interpreting his own arguments in a way that would make them valid.

This way of interpreting the arguments involved reading the conditional premise as a bi-conditional or inserting an assumed premise that would create a valid instance of modus ponens. For 


\section{Mark Stone}

example, with respect to the second argument Burke would claim that the unstated premise is "If human beings are not uniquely rational (as Darwinism has shown), then human beings do not have moral dignity." Rachels, however, emphasizes that "the claim that Darwinism undermines traditional morality is not the claim that it entails that the doctrine of human dignity is false" (Rachels 1990: 97). Furthermore, the explicit conditional statement is a premise in the original argument because it captures the way in which the notion of being created in the image of God and human rationality are being used to support the doctrine of human dignity. They are not presented as necessary conditions for it, but as reasons for believing in human dignity. So the form of denying the antecedent fairly represents the argumentative structure of Rachels's main arguments that undermine support for the claim that human beings have moral dignity. With these arguments Rachels is not inviting those who make these arguments to offer other reasons to support the claim that human beings have moral dignity. He is purposefully rejecting this claim because in his view the implication of Darwinism is that it is false. His arguments should not be construed as fallacious arguments because they are inductive arguments in which the premises provide logical support for the conclusion that human beings do not have moral dignity. John Locke's arguments for rejecting innate principles offer another good example of effective argumentation that involves denying the antecedent.

Before he presents his positive argument that experience is the source of all our ideas, Locke finds it necessary to counter the claim that some ideas or principles are innate. So An Essay Concerning Human Understanding (Book I, Chapter II) begins with a series of arguments to demonstrate that there are no innate principles. Using Rachels's language we might say that Locke wants first to undermine the view of Descartes and others who assert the existence of innate principles. The main argument that Locke attacks is that universal consent about principles proves them innate. "There is nothing more commonly taken for granted," Locke explains,

than that there are certain Principles both Speculative and Practical (for they speak of both) universally agreed upon by all Mankind: which therefore they argue, must needs be the constant Impressions, which the Souls of Men receive in their first Beings, and which they bring into the World with them, as necessarily and really as they do any of their inherent faculties. (Locke 1975: 49) 
Part of Locke's argument against these innate principles aims to undermine the position that there are innate principles by taking away its support. Locke declares that "this Argument of Universal Consent, which is made use of, to prove innate Principles, seems to me a Demonstration that there are none such: Because there are none to which all Mankind give an Universal Assent" (Locke 1975: 49). Locke agrees that his opponents believe that universal assent to a principle is a sufficient condition for saying it is innate. But he denies that there are principles that secure universal consent. I think this argument is correctly represented as an example of denying the antecedent:

If there are principles that have universal agreement, then these principles must be innate.

But there are no principles that have universal agreement.

Therefore, these principles are not innate.

This argument does not "demonstrate" that there are no innate principles, but it effectively undermines the argument presented by those who believe that there are innate principles. I think that Locke implicitly recognizes that this reasoning is not a proof because he says that it "seems to me a demonstration that there are none such"(my emphasis). Moreover, he is not content with this argument alone because he also disagrees with the conditional premise that their argument is based on as well. He says the argument from universal consent "has this Misfortune in it, That if it were true in matter of Fact, there were certain Truths, wherein all mankind agreed, it would not prove them innate" (Locke 1975: 49). His empiricist account of the origin of ideas and truths will provide an alternative explanation how such agreement as we have comes about.

Locke's argumentation in this section of the Essay illustrates the points that have been argued for in this paper. First, his argument shows that a legitimate use of denying the antecedent occurs as a response to a previous argument. Second, it is clear that he presents his arguments as a way of undermining the conclusion drawn by his argumentative opponents that there are innate principles. For Locke these arguments are not a dialectical manoeuvre to prompt them to suggest other and better reasons for believing in innate principles. They are part of an argumentative strategy that effectively provides reasons for rejecting the truth of innate principles.

The arguments presented by Rachels and Locke both illustrate the way in which denying the antecedent is an effective 


\section{Mark Stone}

argument strategy. It is an effective form of argument that can be used to undermine an arguer's position by taking away the support offered for a claim that they disagree with. In these argumentative contexts neither of the authors proves that the position that they disagree with is wrong. He explicitly says that Darwinism does not entail this claim because it is still possible that human beings have moral dignity. He wants to undermine the arguments of those who do believe this so that he can then make a more persuasive case for an ethical position that is consistent with Darwinism and that does not rely on the belief in human dignity. Similarly, Locke does not prove that there are no innate principles because it is still possible that they may exist. By undermining the position that there are innate principles, however, he makes this possibility an improbability. Denying the antecedent is not effective for proving or disproving a position because it is invalid, and if this is how it is employed then it is rightly called a fallacy of reasoning. It is, however, an effective strategy for arguing that an opponent's position is probably false.

\section{Conclusion}

Arguments that take the form of denying the antecedent are generally classified as fallacies of reasoning. Since they have a specific form that is invalid, they are formal fallacies. We have, however, seen reasons that should lead us to hesitate with such an easy classification of all arguments of this form. Although denying the antecedent is an invalid argument form, being invalid is not a sufficient reason for saying that it is a fallacy. The tendency to view it exclusively as a fallacy leads to interpretations of arguments that may be possible, but in other cases are doubtful or implausible. We have seen that in an argumentative context denying the antecedent can be a legitimate response to a previous argument that depends on a conditional. I have further argued for a stronger conclusion that denying the antecedent is an effective argumentative strategy to undermine the conclusion of an argument that depends on a conditional premise. Since many arguments can be fairly represented as having modus ponens structure with a conditional premise, my conclusion means that denying that antecedent has a genuinely wide application. Its effectiveness is not limited to a dialectical function of forcing an arguer to look for other reasons for her position. Its effectiveness extends to reducing the probability of this position relative to the reasons that may support it. The premises of an argument that denies the antecedent, if true, do provide inductive strength for their 
conclusion that the opponent's position is probably false. I have further provided significant examples of argumentative reasoning from Rachels and Locke that shows the effectiveness of denying the antecedent as a way of undermining an opposing philosophical position. Does this argumentative strategy prove that the position is false? No, but by undermining all the support that has been offered for the position, the argument makes the position improbable. Consequently, denying the antecedent is neither defective nor deceptive. In this role denying the antecedent is no fallacy in reasoning. It is a legitimate and effective inductive argument strategy.

\section{Acknowledgements}

I would like to acknowledge the beneficial comments by a reviewer for the journal on previous drafts of the paper. I would also like to thank J. Aaron Simmons for his helpful comments on an earlier draft of the paper.

\section{References}

Adler, J.E. (1994). Fallacies and alternative interpretations. Australasian Journal of Philosophy, 72(3): 271-282.

Burke, M.B. (1994). Denying the antecedent: A common fallacy? Informal Logic, 16(1): 23-30.

Copi, I.M., \& Cohen, C. (2009). Introduction to Logic (13th ed.). Upper Saddle River, New Jersey: Pearson Prentice Hall.

Finocchiaro, M.A. (2005). Fallacies and the evaluation of reasoning. In M.A. Finocchiaro (Ed.), Arguments about Arguments: Systematic, Critical, and Historical Essays in Logical Theory (pp. 113-120). Cambridge: Cambridge University Press. (Reprinted from American Philosophical Quarterly, 1981, January, 18: 13-22)

Floridi, L. (2009). Logical fallacies as informational shortcuts. Synthese, 167(2): 317-325.

George, R. (1983). A postscript on fallacies. Journal of Philosophical Logic, 12(3): 319-325.

Godden, D.M., \& Walton, D. (2004). Denying the antecedent as a legitimate argumentative strategy: A dialectical model. Informal Logic, 24(3): 219-243.

Govier, T. (2001). A Practical Study of Argument (5th ed.).

Stamford, CT: Wadsworth, Thomson Learning.

Grice, P. (1989). Studies in the Way of Words. Cambridge: Harvard University Press. 
Hamblin, C.L. (1970). Fallacies. London: Methuen.

Hitchcock, D. (1995). Did Jesus commit a fallacy? Informal Logic, 17(2): 297-302.

Locke, J. (1975). An Essay Concerning Human Understanding (P.H. Nidditch, Ed.). Oxford: Oxford University Press.

Moldovan, A. (2009). Pragmatic considerations in the interpretation of denying the antecedent. Informal Logic, 29(3): 309-326.

Rachels, J. (1990). Created from Animals, the Moral Implications of Darwinism. Oxford: Oxford University Press.

Ryle, G. (1971). "If," "So," and "Because." In G. Ryle, Collected Papers, 1929-1968, vol. II, pp. 237-241. London: Hutchinson \& Co. Ltd. (Reprinted from "If," "So," and "Because." In M. Black (Ed.), Philosophical Analysis, pp. 302-318. Englewood Cliffs, N.J.: Prentice-Hall, Inc.) 